\title{
Factors inducing regeneration response in oat (Avena sativa L.) anther culture
}

\author{
Marzena Warchoł ${ }^{1}$ - Ilona Czyczyło-Mysza ${ }^{1}$ - Izabela Marcińska ${ }^{1} \cdot$ Kinga Dziurka $^{1}$ • Angelika Noga ${ }^{1}$. \\ Kamila Kapłoniak ${ }^{1}$. Marta Pilipowicz ${ }^{1} \cdot$ Edyta Skrzypek $^{1}$ (i)
}

Received: 24 October 2018 / Accepted: 12 April 2019 / Published online: 20 May 2019 / Editor: Yong Eui Choi

(C) The Author(s) 2019

\begin{abstract}
The efficiency of embryogenesis of anther culture was compared using four cultivars of oat (Avena sativa L.): 'Akt', 'Bingo', 'Bajka', and 'Chwat'. Despite the high resistance of oat to the process of androgenesis, all tested cultivars produced embryo-like structures and only two of them, 'Akt' and 'Chwat', produced fertile doubled haploid plants. A strong cultivar dependency was observed during induction of androgenesis. Further, cold pretreatment together with high temperature shock enhanced the efficiency of this technique. The highest number of embryo-like structures and haploid plants was obtained from $c v$. 'Chwat' (3.6\% and $0.8 \%$, respectively). Embryo-like structure formation also depended on the distance from the base of the flag leaf to the penultimate leaf of the panicle. Most of them were observed on anthers harvested from panicles of which the distance from the base of the flag leaf to the penultimate leaf was less than $4 \mathrm{~cm}$. The presence of the induction medium supplemented with different plant growth regulators was essential for the induction of embryo-like structures but did not increase the production of haploid plants and doubled haploid lines. The highest number of embryo-like structures and plants was obtained on W14 medium with the addition of $2.0 \mathrm{mg} / \mathrm{dm}^{3}$ 2,4-dichlorophenoxyacetic acid and $0.5 \mathrm{mg} / \mathrm{dm}^{3}$ kinetin $(2.7 \%)$. The low haploid plant regeneration rate (from 0.03 to $0.05 \%$ ) still limits the practical application of anther culture for the production of doubled haploid lines in oat.
\end{abstract}

Keywords Oat $\cdot$ Androgenesis $\cdot$ Pretreatment $\cdot$ Embryo-like structures $\cdot$ Plant growth regulators

\section{Introduction}

In vitro production of doubled haploid (DH) plants through androgenesis induction is a promising and convenient alternative to traditionally used techniques for rapid production of fully homozygous plants for breeding programs, marker identification, and gene mapping. A significant advantage is that the system not only speeds up the process of obtaining homozygosity but also increases selection efficiency (Islam and Tuteja 2012). Androgenesis is defined as a developmental pathway, alternative to zygotic embryogenesis, driven by a shift of the normal gametophytic

Electronic supplementary material The online version of this article (https://doi.org/10.1007/s11627-019-09987-1) contains supplementary material, which is available to authorized users.

Edyta Skrzypek

e.skrzypek@ifr-pan.edu.pl

1 Polish Academy of Sciences, Department of Biotechnology, The Franciszek Górski Institute of Plant Physiology, Niezapominajek 21, 30-239 Krakow, Poland development of microspore into the sporophytic development in which embryos and plants are inherited with the genetic traits from the male donor plant. There are two basic methods of androgenesis: anther and isolated microspore cultures. The former involves culturing whole anthers, whereas in the latter, microspores are isolated from anthers prior to in vitro culture (Khound et al. 2013).

In recent years, androgenesis-based methods have been particularly successful in Solanaceae, Brassicaceae, and Gramineae. Nevertheless, only a few species, such as barley (Hordeum vulgare L.), rape (Brassica napus L.), tobacco (Nicotiana spp.), wheat (Triticum aestivum L.), pepper (Capsicum annum), and rice (Oryza sativa), found application in breeding programs due to their high regenerative capacity and were considered an ideal source of information in microspore embryogenesis research (Forster et al. 2007). There are many reviews explaining the production and application of DH plants through androgenesis (Maluszynski et al. 2003; Forster et al. 2007; Germanà 2011). Nevertheless, scientifically or economically important species, woody plants or Leguminosae species, still remain resistant to androgenesis induction (Skrzypek et al. 2008; Germanà 2009). 
Haploid plants (HPs) of oat (Avena sativa L.) can be produced by hybridizations either with maize (Sidhu et al. 2006; Marcińska et al. 2013; Nowakowska et al. 2015; Warchoł et al. 2016) or with pearl millet (Ishii et al. 2013) and by androgenesis in microspore/anther culture (Rines et al. 1997; Kiviharju et al. 2005; Kiviharju et al. 2017). Pioneering work on oat androgenesis was carried out by Rines (1983), who obtained the first three plants (one haploid and two diploids) from 65,000 anthers of the cultivar 'Stout'. In the 1990s, successful plant recovery from oat anthers was reported by Sun et al. (1991), who recovered 12 green oat plants, including two haploids and one euploid. Kiviharju and Pehu (1998) reported many anther-derived embryos without successful plant regeneration. Later, Kiviharju et al. (2005) improved the anther culture method by several adjustments to older methods and reported up to 30 green plants per 100 anthers cultured for an individual cross. Recently, ŚlusarkiewiczJarzina and Ponitka (2007) have described plants derived from anther culture from Polish oat cultivars.

Androgenesis, like other haploid-inducing techniques, is influenced by several endogenous and exogenous factors. Genotype, physiological state, and growth conditions of donor plants, stage of male gametes, pretreatment of flower buds or anthers, in vitro culture medium composition, and physical factors during tissue culture together with their interactions are the main factors determining the androgenetic response in in vitro culture (Islam and Tuteja 2012; Murovec and Bohanec 2012; Ferrie et al. 2014). The application of suitable physiochemical factors promotes stress response that arrests microspores or young pollen grains in their gametophytic pathway. Temperature pretreatment, sucrose and nitrogen starvation, and osmotic stress are the most commonly used triggering factors. Depending on the plant species and genotype, temperature stress can be applied by subjecting excised flower buds, whole inflorescences, or excised anthers to low (barley, wheat, maize, rice, triticale, rye) or high (Brassica species, tobacco, wheat) temperatures for several hours or days (Maluszynski et al. 2003; Maraschin et al. 2005). Ślusarkiewicz-Jarzina and Ponitka (2007) reported harvesting and cold-treating oat tillers at $4{ }^{\circ} \mathrm{C}$ for a few days in N6 mineral salt medium (Chu et al. 1975) with $2.0 \mathrm{mg} / \mathrm{dm}^{3}$ 2,4-D. Sidhu and Davies (2009) also used $4^{\circ} \mathrm{C}$ temperature for oat androgenesis induction for 6-9 wk. Temperature pretreatment is usually conducted at low temperatures, but sometimes, heat shock conditions of $32^{\circ} \mathrm{C}$ for hours or days are used in oat anther cultures (Kiviharju et al. 1998). Anthers were also heat shocked at $35^{\circ} \mathrm{C}$ for $24 \mathrm{~h}$ immediately after placing them on induction media (Rines 1983).

The aim of the experiments was the induction of androgenesis in anther culture of oat. The effects of cultivar, pretreatment, induction medium, and distance from the base of the flag leaf to the penultimate leaf of the panicle on the androgenesis efficiency were tested.

\section{Materials and methods}

Oat (Avena sativa L.) cultivars derived from Strzelce Plant Breeding Ltd., PBAI Group, Strzelce, Łódź Voivodeship, Poland were used as sources of anthers for studying androgenic abilities. Seeds of each genotype were sown singly into a mixture of soil with sand $(3: 1 \mathrm{v} / \mathrm{v})$ in $3 \mathrm{dm}^{3}$ pots. Donor plants were grown under controlled conditions at $21 / 17^{\circ} \mathrm{C}$ day/night, 16-h photoperiod, in a greenhouse under natural (solar) light during the day and sodium lamps $(400 \mathrm{~W}$, Philips SON-T AGRO, Philips Lighting, Eidhoven, the Netherlands) between 6 and 8 a.m. and additionally between 6 and 10 p.m. on cloudy days. Plants were fertilized with a liquid medium once a w (Hoagland and Arnon 1938).

In the first experiment, 175 tillers of 'Akt', 'Bingo', 'Bajka', and 'Chwat' were cut when the panicle was enclosed within the leaf sheath (Fig. 1a). At this time, the majority of microspores were at the late uninucleate (Fig. $1 b$ ) to early binucleate stage (Fig. 1c). To correlate the stage of microspore development with tiller morphology, microspores were observed under a light microscope (SMZ 1500, Nikon, Tokyo, Japan) and the distance from the base of the flag leaf to the penultimate leaf of the panicle was measured and four distance classes were designated: (A) $0.0-4.0 \mathrm{~cm}$, (B) $4.1-8.0$, (C) 8.1-12.0, and (D) 12.1-16.0.

Oat tillers were covered with aluminum bags (Fig. 1d), dipped in Hoagland and Arnon (1938) liquid medium for 2 and $3 \mathrm{wk}$ at $4{ }^{\circ} \mathrm{C}$. Next panicles were disinfected in $70 \%(\mathrm{v} / \mathrm{v})$ ethanol $(1 \mathrm{~min})$, then in a $2.5 \%(\mathrm{w} / \mathrm{v})$ solution of calcium hypochlorite $\left(65 \% \mathrm{Ca}(\mathrm{OCl})_{2}\right.$ commercial product, SigmaAldrich ${ }^{\circ}$, Darmstadt, Germany) (7 min), and subsequently washed three times with sterile water. For embryo-like structures (ELS) induction, anthers were aseptically isolated on C17 medium (Wang and $\mathrm{Hu}$ 1984) with the addition of 4amino-3,5,6-trichloropicolinic acid (picloram), 2-methoxy3,6-dichlorobenzoic acid (dicamba), and kinetin. All growth regulators were added to the medium at a concentration of $0.5 \mathrm{mg} / \mathrm{dm}^{3}$. For each oat cultivar, 20 replicate Petri plates $(6 \mathrm{~cm})$, each containing 70-120 anthers, were cultured.

The cultivars 'Bingo' and 'Chwat', which produced the highest number of ELS, were selected for the second experiment. Donor plants were grown in a greenhouse (conditions as above). The stage of microspore development was determined using the same approach used in the first experiment. Tillers of the donor plants (119 of 'Bingo' and 114 of 'Chwat') were placed in Hoagland liquid medium and cooled at $4^{\circ} \mathrm{C}$ for 2 and $3 \mathrm{wk}$, and then half of them were kept at $32^{\circ} \mathrm{C}$ for $24 \mathrm{~h}$. Panicles were disinfected as in the first experiment. Then, anthers were aseptically isolated and placed on $\mathrm{C} 17$ medium (Wang and $\mathrm{Hu} 1984$ ) containing: $0.5 \mathrm{mg} / \mathrm{dm}^{3}$ picloram, $0.5 \mathrm{mg} / \mathrm{dm}^{3}$ dicamba, $0.5 \mathrm{mg} / \mathrm{dm}^{3}$ kinetin $(\mathrm{C} 17-1)$, or $0.5 \mathrm{mg} / \mathrm{dm}^{3}$ picloram, $0.5 \mathrm{mg} / \mathrm{dm}^{3}$ dicamba, $0.5 \mathrm{mg} / \mathrm{dm}^{3}$ BAP (C17-2) and W14 medium (Ouyang et al. 1989) 
Figure 1. Androgenesis in oat (Avena sativa L.) anther culture: (a) tiller of 'Chwat' with the panicle enclosed within leaf sheath (NPL - node of the penultimate leaf, NFL — node of the flag leaf, ID - internode distance); (b) microspore in the uninucleated stage; $(c)$ microspore in the binucleated stage; $(d)$ tillers of 'Chwat' covered with an aluminum bag prepared for pretreatment; $(e)$ dehisced anther releasing microspores; $(f)$ anthers with ELS developed indicated by arrows; $(g-i)$ anthers with ELS; regenerated HP: $(j)$ on W14-5 medium, $(k)$ on MS medium, $(l)$ in perlite, $(m)$ in soil, and $(n-o)$ $\mathrm{DH}$ plants maturing into greenhouse conditions.
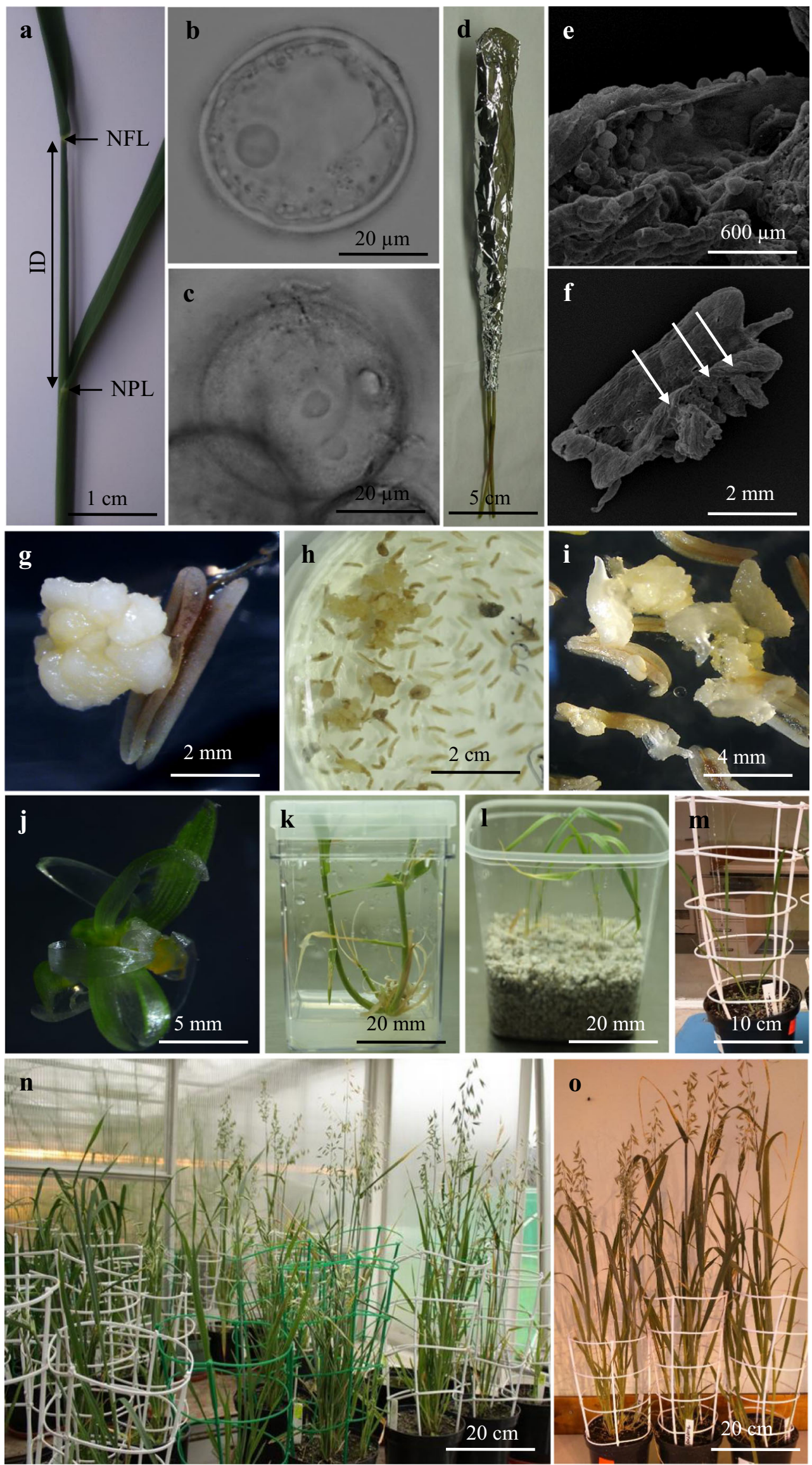

Springer 
containing: $5.0 \mathrm{mg} / \mathrm{dm}^{3}$ 2,4-dichlorophenoxyacetic acid (2,4D), $2.0 \mathrm{mg} / \mathrm{dm}^{3}$ naphthyl-1-acetic acid (NAA), $0.5 \mathrm{mg} / \mathrm{dm}^{3}$ kinetin (W14-1), $5.0 \mathrm{mg} / \mathrm{dm}^{3}$ 2,4-D, $2.0 \mathrm{mg} / \mathrm{dm}^{3} \mathrm{NAA}$, $0.5 \mathrm{mg} / \mathrm{dm}^{3}$ 6-benzylaminopurine (BAP) (W14-2), $5.0 \mathrm{mg} /$ $\mathrm{dm}^{3} 2,4-\mathrm{D}, 0.5 \mathrm{mg} / \mathrm{dm}^{3}$ kinetin (W14-3), $5.0 \mathrm{mg} / \mathrm{dm}^{3}$ 2,4-D, $0.5 \mathrm{mg} / \mathrm{dm}^{3}$ BAP (W14-4), $2.0 \mathrm{mg} / \mathrm{dm}^{3} 2,4-\mathrm{D}, 0.5 \mathrm{mg} / \mathrm{dm}^{3}$ kinetin (W14-5), and $2.0 \mathrm{mg} / \mathrm{dm}^{3}$ 2,4-D, $0.5 \mathrm{mg} / \mathrm{dm}^{3}$ BAP (W14-6). For each oat cultivar, ten replicate Petri plates $(6 \mathrm{~cm})$, each containing 70 anthers, were cultured.

Media in both experiments were enriched with $9 \%$ maltose, solidified with $0.6 \%$ agar, and the $\mathrm{pH}$ was adjusted to 6.0. Anther cultures were incubated in the dark at $28 \pm 1{ }^{\circ} \mathrm{C}$. Embryogenic structures were observed after about 6-8 wk under a light microscope (SMZ 1500, Nikon, Tokyo, Japan) and using a scanning electron microscope (Jeol model JSM 5410, Tokyo, Japan). The efficiency of androgenesis was determined as the number of ELS obtained from 100 anthers. Regenerated HPs were transferred into Magenta boxes containing solidified ( $0.6 \%$ agar) MS medium with half the original concentrations (Murashige and Skoog 1962) and without growth regulators. They were maintained at $21 \pm 2{ }^{\circ} \mathrm{C}$ and light intensity of $60 \mu \mathrm{mol} \mathrm{m} \mathrm{m}^{-2} \mathrm{~s}^{-1}(16 / 8 \mathrm{~h} \mathrm{light/dark})$. Subsequently, HPs were acclimated to ex vitro conditions by transferring them to moist perlite (Zakłady GórniczoMetalowe Zębiec S.A., Zębiec, Poland) and then to the soil (Ziemia uniwersalna, Ekoziem, Jurków, Poland).

Ploidy level of plants was evaluated before and after colchicine treatment using a MACSQuant flow cytometer (MACSQuant, Miltenyi Biotec GmbH, Bergisch Gladbach, Germany), equipped with air-cooled laser $(488 \mathrm{~nm})$ and MACSQuantifyTM software, as described by Warchoł et al. (2016). After colchicine treatment, all plants were grown in $3 \mathrm{dm}^{3}$ pots with the mixture of soil with sand $(3: 1 \mathrm{v} / \mathrm{v})$ to maturity in a greenhouse (conditions as above) and bagged individually to ensure self-fertilization.

All reagents used in the experiment were obtained from Sigma-Aldrich®, Poznań, Poland.

Statistical analysis Data of ELS, HPs, and DHs were analyzed using analysis of variance (ANOVA) with STATISTICA 10.0 (Stat-Soft, Inc., Tulsa, OK). Mean comparisons were carried out using Duncan's multiple range test.

\section{Results}

Pretreatment conditions, distance from the base of the flag leaf to the penultimate leaf of the panicle, and induction media were tested to produce oat DH lines using anther culture of four cultivars. In the first experiment, over 8000 anthers were isolated on the induction medium (Table 1). About 4 to $6 \mathrm{wk}$ after culturing, anthers dehisced (Fig. 1e) and ELS started to emerge (Fig. 1f). In total, 92 ELS were obtained in all tested oat cultivars (Table 1 ; Fig. $1 g-i$ ). The highest number of ELS was obtained from 'Chwat' and 'Bingo' (3.6\% and 1.6\%, respectively), and only two cultivars, 'Akt' and 'Chwat', produced HPs ( $0.5 \%$ and $0.8 \%$, respectively). All HPs were green (Fig. $1 j-m$ ). The ploidy of the control diploid oat plants (Supplementary Fig. 1a) was compared with plants before (Supplementary Fig. 1b) and after colchicine treatment (Supplementary Fig. 1c). Cytometric analysis confirmed that the colchicine treatment doubled chromosomes of all tested plants. Six of 14 plants produced 1537 seeds and were considered to be DH lines (Fig. 1n,o). The analysis of variance presented in Table 2 showed that ELS development depended significantly on the cultivar and distance from the base of the flag leaf to the penultimate leaf of the panicle.

Of all tested cultivars, 'Chwat' developed the highest number of ELS irrespective of the tested distances of the panicle which were measured from the base of the flag leaf to the penultimate leaf. However, the majority of ELS formation was observed on anthers derived from the youngest panicles (A $0.0-4.0 \mathrm{~cm}$ ) (Fig. 2a). This stage of plant development was also favorable for ELS formation in all tested cultivars, especially for $c v$. 'Akt', which produced ELS only at this stage of development. The number of ELS was not statistically dependent on the distance from the base of the flag leaf to the penultimate leaf of the panicle in cvs. 'Bajka' and 'Bingo'. Cvs. 'Akt', 'Bajka', and 'Bingo' did not form ELS when anthers were isolated at distance C (8.1-12.0). HPs and DHs were favorably induced in anthers cultured from the youngest panicles collected at the measured distance A $(0.0-4.0 \mathrm{~cm})$ of the panicles (Fig. 2b).

Cvs. 'Bingo' and 'Chwat' were selected for the second experiment due to their high efficiency in ELS production. Pretreatment conditions (time of cooling together with temperature shock) as well as induction media were

Table 1. The effect of the genotype on the production efficiency of ELS, HP, and DH lines in oat anther cultures

\begin{tabular}{lllllllll}
\hline Cultivar & $\begin{array}{l}\text { Number of } \\
\text { panicles }\end{array}$ & $\begin{array}{l}\text { Number of } \\
\text { anthers }\end{array}$ & $\begin{array}{l}\text { Number } \\
\text { of ELS }\end{array}$ & ELS/anthers $(\% \pm \mathrm{SE})$ & HP & HP/anthers $(\% \pm \mathrm{SE})$ & DH plants & $\begin{array}{l}\text { DH plants/anthers }(\% \pm \text { SE) } \\
\text { Number } \\
\text { of seeds }\end{array}$ \\
\hline Akt & 60 & 2367 & 11 & $0.7 \pm 0.3$ & 4 & $0.5 \pm 0.4$ & 4 & $0.5 \pm 0.4$ \\
Bajka & 54 & 2856 & 12 & $0.5 \pm 0.1$ & 0 & 0 & 0 & 0 \\
Bingo & 37 & 1578 & 21 & $1.6 \pm 0.4$ & 0 & 0 & 0 & 0 \\
Chwat & 24 & 1475 & 49 & $3.6 \pm 0.7$ & 10 & $0.8 \pm 0.4$ & 2 & $0.4 \pm 0.2$ \\
\hline
\end{tabular}


Table 2. Analysis of variance of the effect of cultivar, distance from the base of the flag leaf to the penultimate leaf of the panicle, and pretreatment on the percentage of ELS, HP, and DH

Figure 2. The regeneration response of oat (Avena sativa L.) depending on the panicle maturity determined by the internode distance: number of $(a)$ ELS and (b) HP and DH lines. Bars represent mean values $\pm \mathrm{SE}$.

\begin{tabular}{|c|c|c|c|c|c|}
\hline Dependent variable & Independent variable & SS & $\mathrm{df}$ & $F$ & $p$ \\
\hline \multirow[t]{3}{*}{ ELS } & Cultivar & 192.525 & 3 & 14.161 & $0.000 * * *$ \\
\hline & $\begin{array}{l}\text { Distance from the base of the flag leaf to } \\
\text { the penultimate leaf of the panicle }\end{array}$ & 51.261 & 3 & 3.198 & $0.025^{*}$ \\
\hline & Pretreatment & 7.321 & 1 & 1.307 & $0.254 \mathrm{~ns}$ \\
\hline \multirow[t]{3}{*}{ HP } & Cultivar & 16.759 & 3 & 1.826 & $0.144 \mathrm{~ns}$ \\
\hline & $\begin{array}{l}\text { Distance from the base of the flag leaf to } \\
\text { the penultimate leaf of the panicle }\end{array}$ & 11.854 & 3 & 1.280 & $0.283 \mathrm{~ns}$ \\
\hline & Pretreatment & 0.056 & 1 & 0.017 & $0.892 \mathrm{~ns}$ \\
\hline \multirow[t]{3}{*}{ DH lines } & Cultivar & 8.347 & 3 & 0.935 & $0.425 \mathrm{~ns}$ \\
\hline & $\begin{array}{l}\text { Distance from the base of the flag leaf to } \\
\text { the penultimate leaf of the panicle }\end{array}$ & 10.859 & 3 & 1.222 & $0.303 \mathrm{~ns}$ \\
\hline & Pretreatment & 0.056 & 1 & 0.018 & $0.892 \mathrm{~ns}$ \\
\hline
\end{tabular}

$S S$ sum of squares, $d f$ degrees of freedom, $M S$ mean squares, $n s$ not significant

*Significant at $p \leq 0.05 ; * * *$ significant at $p \leq 0.001$

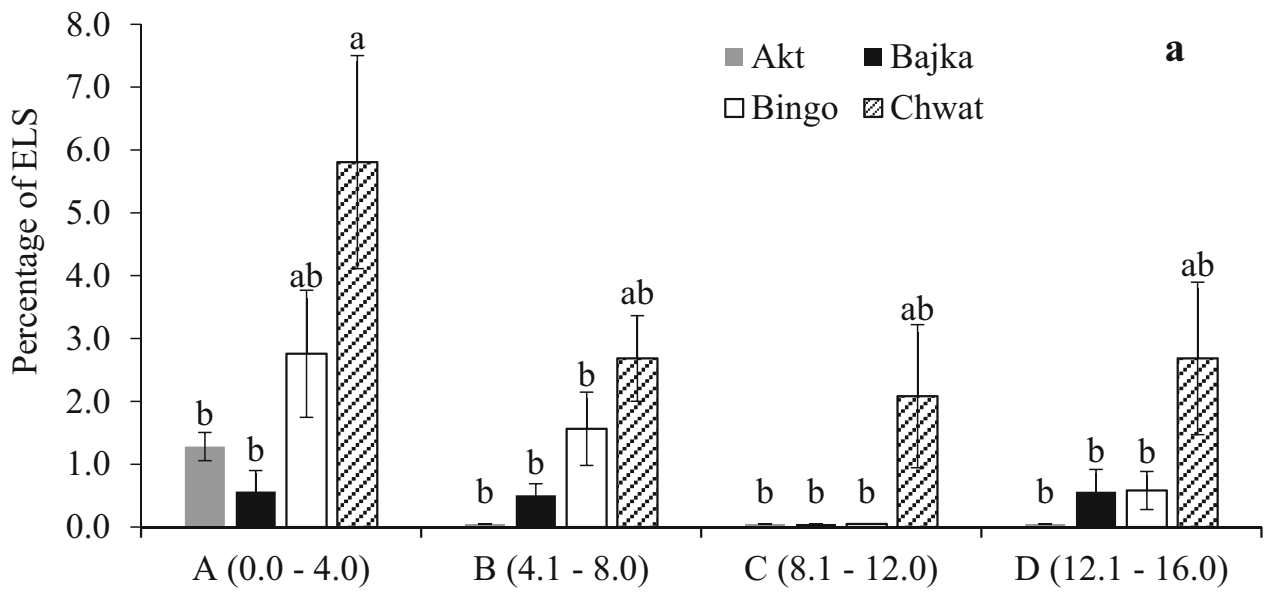

The distance from the base of the flag leaf to the penultimate leaf of the panicle $[\mathrm{cm}]$

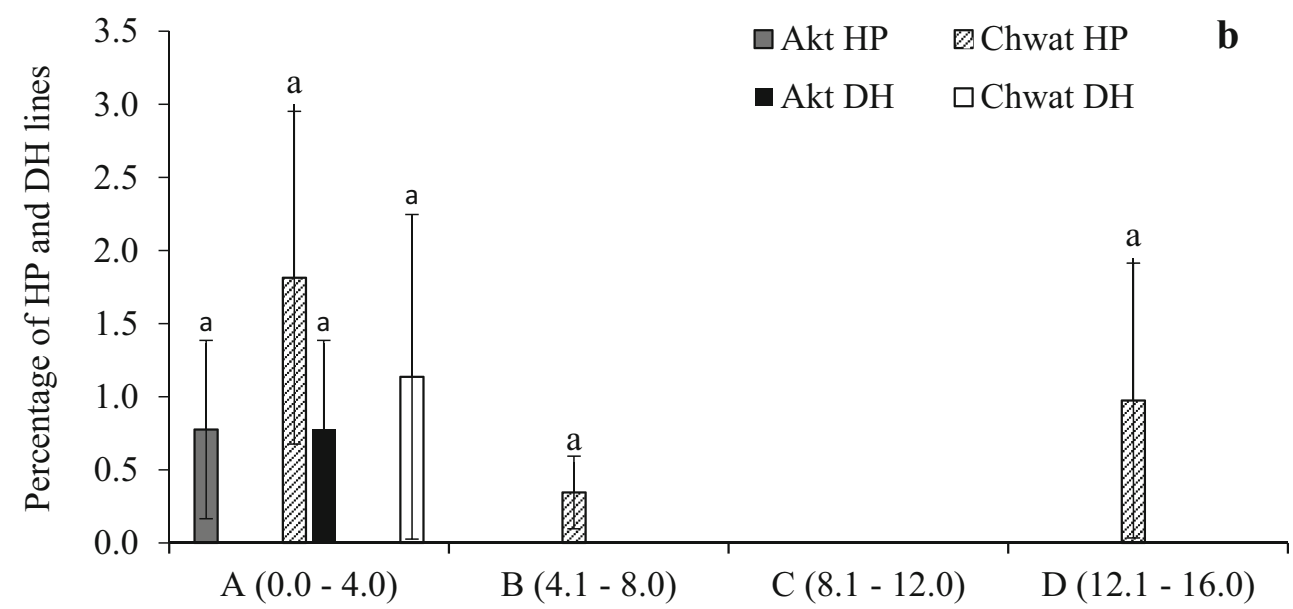

The distance from the base of the flag leaf to the penultimate leaf of the panicle $[\mathrm{cm}]$ 
Table 3. The effect of the genotype on the production efficiency of ELS, HP, and DH lines in oat anther cultures

\begin{tabular}{|c|c|c|c|c|c|c|c|c|c|}
\hline Cultivar & $\begin{array}{l}\text { Number } \\
\text { of panicles }\end{array}$ & $\begin{array}{l}\text { Number } \\
\text { of anthers }\end{array}$ & ELS & ELS/anthers $(\% \pm \mathrm{SE})$ & HP & $\mathrm{HP} /$ anthers $(\% \pm \mathrm{SE})$ & DH plants & DH plants/anthers $(\% \pm \mathrm{SE})$ & $\begin{array}{l}\text { Number } \\
\text { of seeds }\end{array}$ \\
\hline Bingo & 119 & 5548 & 29 & $0.5 \pm 0.1$ & 0 & 0 & 0 & 0 & 0 \\
\hline Chwat & 114 & 5674 & 77 & $1.1 \pm 0.2$ & 7 & $0.1 \pm 0.05$ & 2 & $0.03 \pm 0.03$ & 46 \\
\hline
\end{tabular}

tested to increase androgenesis efficiency. Both cultivars produced ELS in this experiment ( $c v$. 'Bingo'- $0.5 \%, c v$. 'Chwat'-1.1\%). Green HPs were obtained only from $c v$. 'Chwat' $(0.1 \%)$ and 2 DHs produced 46 seeds (Table 3 ). Albino plants were absent as similar to the observations of the first experiment.

The analysis of variance presented in Table 4 showed significant differences between the cultivars, pretreatment, and induction medium only in the case of ELS production. Anther response to pretreatment was observed in both cultivars (Fig. $3 a$ ). The highest number of ELS (1.7\%) was produced when the panicles of $c v$. 'Chwat' were cooled 2 wk at $4^{\circ} \mathrm{C}$ and then kept $24 \mathrm{~h}$ at $32^{\circ} \mathrm{C}$. Pretreatment was not statistically significant for ELS formation by $c v$. 'Bingo'; however, the majority of ELS formed (0.7\%) after cooling for $3 \mathrm{wk}$ only at $4^{\circ} \mathrm{C}$. Pretreatment was not statistically significant for HPs and $\mathrm{DH}$ line formation; however, the majority of HPs formed after cooling for $2 \mathrm{wk}$ only at $4^{\circ} \mathrm{C}$ or when after $2 \mathrm{wk}$ of cooling anthers were kept $24 \mathrm{~h}$ at $32^{\circ} \mathrm{C}(0.21 \%, 0.19 \%$, respectively). $\mathrm{DH}$ lines $(0.14 \%)$ developed only after cooling donor plants at $4^{\circ} \mathrm{C}$ for 2 wk (Fig. $3 b$ ).

The effect of the induction medium on androgenesis efficiency is shown in Fig. 4a. ELS formation was observed on all tested media, except for $c v$. 'Bingo' on W14-3 medium, although not all of the variables were significantly affected. Anthers of $c v$. 'Chwat' developed the highest number of ELS $(2.7 \%)$ on W14-5 medium, whereas W14-1 was more appropriate for androgenesis induction of $c v$. 'Bingo' (1.4\%). HPs formation was observed on three tested media (C17-2, W14-1, W14-5) from ELS $c v$. 'Chwat', whereas DH lines were obtained only on medium W14-1 (0.27\%) (Fig. 4b).

\section{Discussion}

Anther culture has considerable value in shortening the time required to develop homozygous lines, which efficiency is sufficient for breeding purposes for many major crops, e.g., tobacco, brassica, and rice; however, most of the plant species are still recalcitrant to this process. Literature data indicate that oat belongs to the species resistant to androgenesis and strongly dependent on the genotype (Kiviharju et al. 2005, 2017; Ponitka and Ślusarkiewicz-Jarzina 2009). Moreover, low rates of oat DHs production have limited the use of them in various research areas.
The microspore development stage is one of the most important factors affecting the success of ELS formation. In most cases, the uninucleate stage of the microspore or just after the first pollen mitosis, i.e., the early binucleate stage, is the most suitable for androgenic response in cereal crops. The most appropriate developmental stage of microspores can be identified by the size of anthers or by staining anthers with acetocarmine to observe the nuclei under a light microscope (De Cesaro et al. 2009; Sood and Dwivedi 2015). Also, the degree of starch deposition in the microspores was identified as an efficient cytological indicator to determine the microspore maturity (Mayakaduwa and Silva 2017).

In our study, we used a morphometric pretest which is a standardized distance measurement of the panicle to correlate with the microspore development stage. The panicle development stage at the measured distance A (0.0$4.0 \mathrm{~cm})$ proved to be the best for all tested cultivars that responded to induction treatment and formed ELS. Such pretests are useful to establish a correlation between easily observable morphological traits and the microspore maturity within the anthers, e.g., if the tip of the panicle is inside the leaf sheath at the level of the second leaf base, as reported by Kiviharju et al. (1998), it means that floret buds contain anthers or microspores suitable for androgenesis. The androgenesis competence of the microspore development stage varies with the species or cultivars but is relatively limited and was named by Smykal and Pechan

Table 4. Analysis of variance of the effect of cultivar, pretreatment, and induction medium on the percentage of ELS, HP, and DH lines

\begin{tabular}{llllll}
\hline Dependent variable & $\begin{array}{l}\text { Independent } \\
\text { variable }\end{array}$ & SS & df & $F$ & $p$ \\
\hline ELS & Cultivar & 22.904 & 1 & 8.781 & $0.003^{* *}$ \\
& Pretreatment & 21.940 & 3 & 2.774 & $0.042^{*}$ \\
& Induction medium & 38.482 & 7 & 2.107 & $0.044^{*}$ \\
HP & Cultivar & 0.537 & 1 & 3.667 & $0.057 \mathrm{~ns}$ \\
& Pretreatment & 0.612 & 3 & 1.382 & $0.249 \mathrm{~ns}$ \\
\multirow{3}{*}{ DH lines } & Induction medium & 1.340 & 7 & 1.303 & $0.250 \mathrm{~ns}$ \\
& Cultivar & 0.062 & 1 & 0.957 & $0.329 \mathrm{~ns}$ \\
& Pretreatment & 0.225 & 3 & 1.153 & $0.329 \mathrm{~ns}$ \\
& Induction medium & 0.445 & 7 & 0.975 & $0.451 \mathrm{~ns}$ \\
\hline
\end{tabular}

$S S$ sum of squares, $d f$ degrees of freedom, $M S$ mean squares, $n s$ not significant

*Significant at $p \leq 0.05 ; * *$ significant at $p \leq 0.01$ 
Figure 3. The regeneration response of oat (Avena sativa L.) depending on pretreatment: number of $(a)$ ELS and $(b)$ HP and DH lines. Bars represent mean values $\pm \mathrm{SE}$.

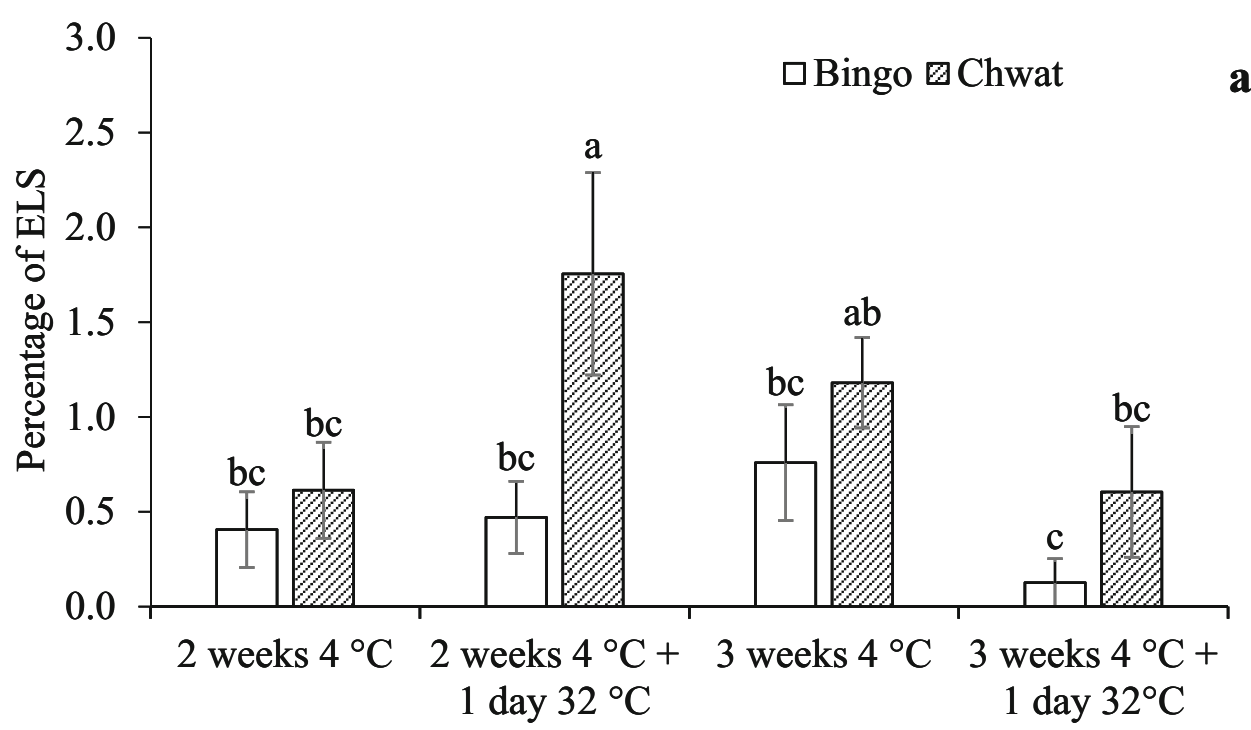

Pretreatment

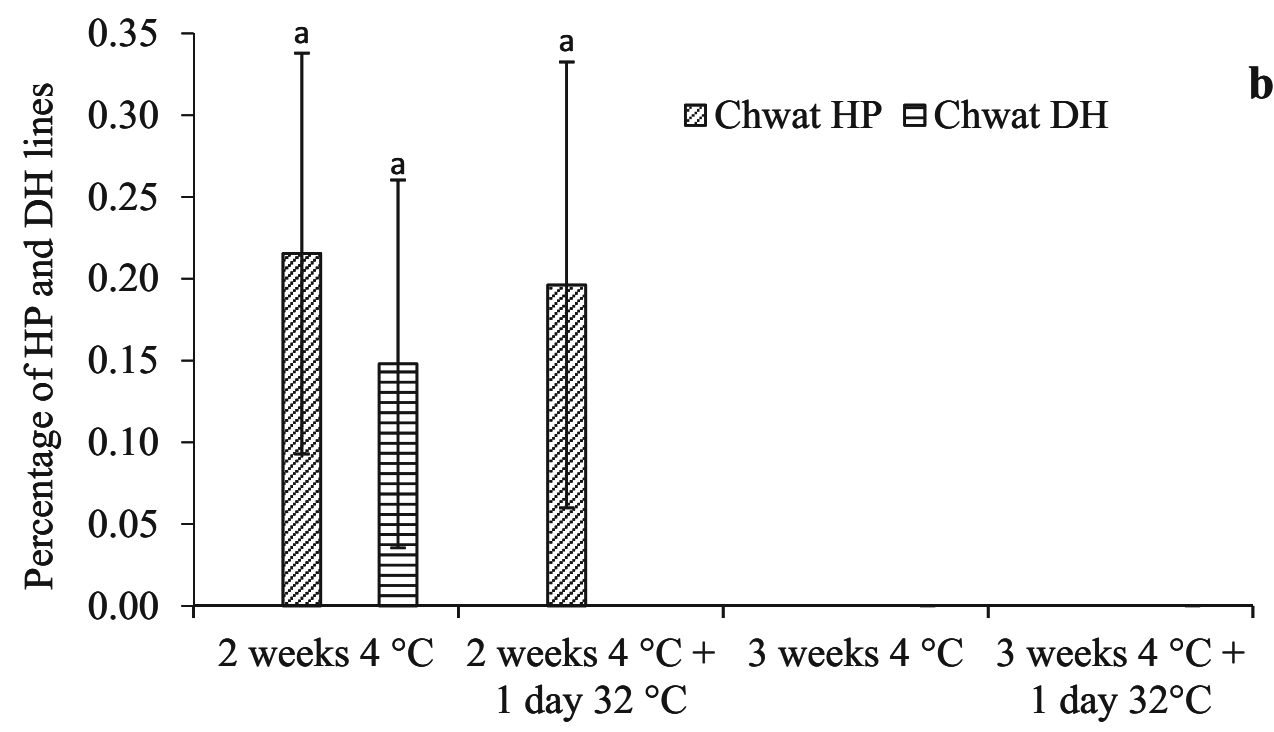

Pretreatment

(2000) as the "development window." In this restricted period, the switch from gametophytic to sporophytic routes happens only between the mononucleate and median binucleate stages of microspores (De Cesaro et al. 2009).

The structural variation of oat panicle shape and morphology accompanied by non-linear microsporogenesis maturation in the panicles makes it difficult to identify anther size with microspores at the appropriate stage. Even the microspores within one anther will vary in their embryogenic competency due to slight differences in the developmental stage (Sood and Dwivedi 2015). Therefore, cytological screening before culture is critical in identifying microspores exactly at the appropriate stage for oat androgenesis.
The change in the developmental pathway of microspores from the normal gametophytic to the sporophytic one is stimulated by physical or chemical preculture treatment applied to whole panicles, single florets, or isolated anthers before in vitro cultures (Hosp et al. 2007). The androgenetic response in crop plants depends on many stress factors, e.g., temperature shock, carbohydrate/nitrogen starvation, or high osmotic pressure. However, it was found that application of these pretreatments might vary depending on the species or even the cultivar (Shariatpanahi et al. 2006). In oat (Avena sativa L.), cut panicles were subjected to cold pretreatment at $4^{\circ} \mathrm{C}$ in the dark for $0,7,14,21$, or $28 \mathrm{~d}$ and heat pretreatment at $32^{\circ} \mathrm{C}$ applied to isolated anthers for 0, 1, 3, 5, or $7 \mathrm{~d}$ (Kiviharju et al. 
Figure 4. The regeneration response of oat (Avena sativa $\mathrm{L}$.) depending on the induction medium: number of $(a)$ ELS and (b) HP and DH lines. Bars represent mean values $\pm \mathrm{SE}$.
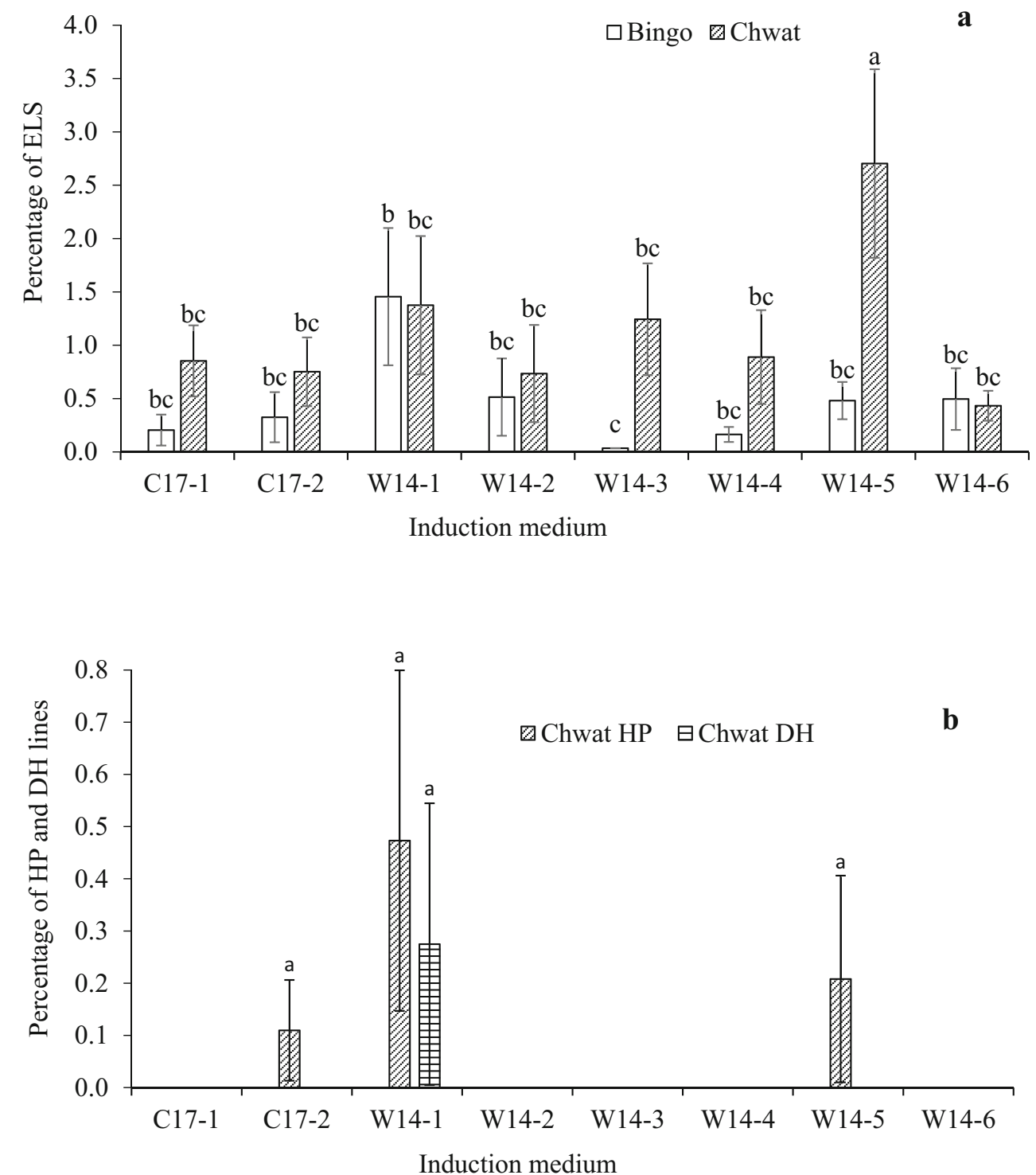

1998). In our study, cold pretreatment combined with thermal shock at $32^{\circ} \mathrm{C}$ for $24 \mathrm{~h}$ was more efficient in reprogramming the gametophytic pathway and inducing androgenesis than cooling alone. Rines (1983) and Kiviharju and Pehu (1998) reported that cold pretreatment did not have a positive impact on the effectiveness of oat anther culture. Furthermore, long cold pretreatment (6-8 wk) may cause high frequency of albino regenerates (Sidhu and Davies 2009). In the study of Kiviharju et al. (1998), heat pretreatment $\left(32^{\circ} \mathrm{C}\right)$ seemed to affect the type of anther response. Five days of heat stress proved to be optimal for Avena sativa L. anther cultures, as they responded with embryogenesis, whereas cultures not treated with heat produced only callus. Some reports described that stress pretreatment was not only needed for switching microspore development, but it could also influence microspore divisions, ELS, and green plant production as well as spontaneous chromosome doubling efficiency (Kasha et al.
2001; Oleszczuk et al. 2006). However, in our study, pretreatment affected only ELS formation.

The composition of the culture media plays a major role in induction of ELS. Numerous studies were evaluating the different components of media, e.g., source of carbon, macronutrients, and micronutrients as well as the type and concentration of growth regulators which could be a decisive factor that stimulated pollen embryogenesis (Ślusarkiewicz-Jarzina and Ponitka 2007; Ferrie et al. 2014; Sood and Dwivedi 2015; Kiviharju et al. 2017). In our experiment, the effect of C17 (Wang and Hu 1984) and W14 (Ouyang et al. 1989) induction media was observed. The same medium compositions were used previously by Ponitka and Ślusarkiewicz-Jarzina (2009), who studied androgenesis of nine oat genotypes and reported that ELS induction efficiency was higher on C17 medium for all genotypes. In contrast to Ponitka and ŚlusarkiewiczJarzina (2009), our experiments showed that more ELS and 
plants regenerated on W14 than on $\mathrm{C} 17$ medium. Kiviharju et al. (2000) indicated that lower concentrations of 2,4-D (2$\left.3 \mathrm{mg} / \mathrm{dm}^{3}\right)$ and kinetin $\left(0.2-0.5 \mathrm{mg} / \mathrm{dm}^{3}\right)$ in the induction media were sufficient for embryo induction. Moreover, kinetin seemed to affect the quality of the induced ELS, promoting formation of regenerable structures, although higher concentrations of cytokinins often caused browning of the anthers.

In the Rines (1983) study, only anthers initially placed on a modified potato extract medium containing $2 \mathrm{mg} / \mathrm{dm}^{3} 2,4-\mathrm{D}$ and $0.5 \mathrm{mg} / \mathrm{dm}^{3}$ kinetin produced plants. The above results are consistent with our observations that the largest number of ELS was formed on W14 medium enriched with $2.0 \mathrm{mg} /$ $\mathrm{dm}^{3} 2,4-\mathrm{D}$ and $0.5 \mathrm{mg} / \mathrm{dm}^{3}$ of kinetin. In addition, all plants on this medium were green, as opposed to the results of Kiviharju et al. (2000), who indicated that the W14 medium favored albino plant production.

\section{Conclusions}

We demonstrated that cold pretreatment in combination with heat treatment for cut oat tillers before anther isolation, the distance from the base of the flag leaf to the penultimate leaf of the panicle, as well as induction medium W14 with $2.0 \mathrm{mg} /$ $\mathrm{dm}^{3}$ 2,4-D and $0.5 \mathrm{mg} / \mathrm{dm}^{3}$ kinetin improved androgenic response. Although the application of anther culture is frequently used in breeding studies, the processes involved in androgenesis are still poorly understood. There is a need to study, understand, and manipulate microspore embryogenesis to develop genotype-independent methods.

Funding information The research was funded by The Franciszek Górski Institute of Plant Physiology, Polish Academy of Sciences.

\section{Compliance with ethical standards}

Conflict of interest The authors declare that they have no conflict of interest.

Open Access This article is distributed under the terms of the Creative Commons Attribution 4.0 International License (http:// creativecommons.org/licenses/by/4.0/), which permits unrestricted use, distribution, and reproduction in any medium, provided you give appropriate credit to the original author(s) and the source, provide a link to the Creative Commons license, and indicate if changes were made.

\section{References}

Chu CC, Wang CC, Sun CS, Hsu C, Yin KC, Chu CY (1975) Establishment of an efficient medium for anther culture of rice through comparative experiments on the nitrogen sources. Sci Sinica 16:659-688

De Cesaro T, Baggio MI, Zanetti A, Suzin M, Augustin L, Brammer SP, Lorczeski EJ, Milach SCK (2009) Haplodiploid androgenetic breeding in oat: genotypic variation in anther size and microspore development stage. Sci Agri (Piracicaba, Braz) 66:118-122

Ferrie AMR, Irmen KI, Beattie AD, Rossnagel BG (2014) Isolated microspore culture of oat (Avena sativa L.) for the production of doubled haploids: effect of pre-culture and post-culture conditions. Plant Cell Tissue Organ Cult 116:89-96

Forster BP, Herberle-Bors E, Kasha KJ, Touraev A (2007) The resurgence of haploids in higher plants. Trends Plant Sci 12:368-375

Germanà MA (2009) Haploids and doubled haploids in fruit trees. In: Touraev A, Forster BP, Jain SM (eds) Advances in haploid production in higher plants. Springer, Heidelberg, pp 241-263

Germanà MA (2011) Anther culture for haploid and doubled haploid production. Plant Cell Tissue Organ Cult 104:283-300

Hoagland DR, Arnon DI (1938) A water culture method for growing plants without soil. California Agricultural Experiment Station Circulation 347:1-39

Hosp J, Maraschin SF, Touraev A, Boutilier K (2007) Functional genomics of microspore embryogenesis. Euphytica 158:275-285

Ishii T, Tanaka H, Eltayeb AE, Tsujimoto H (2013) Wide hybridization between oat and pearl millet belonging to different subfamilies of Poaceae. Plant Reprod 26:25-32

Islam SMS, Tuteja N (2012) Production of abiotic stress tolerant fertile transgenic plants using androgenesis and genetic transformation methods in cereal crops. In: Tuteja N, Gill SS (eds) Crop improvement under adverse conditions. Springer, New York, pp 213-229

Kasha KJ, Hu TC, Oro R, Simion E, Shim YS (2001) Nuclear fusion leads to chromosome doubling during mannitol pretreatment of barley (Hordeum vulgare L.) microspores. J Exp Bot 52:1227-1238

Khound R, Santra M, Baenziger PS, Santra DK (2013) Effect of coldmediated pre-treatment on microspore culture in winter and spring wheat. Am J Plant Sci 4:2259-2264

Kiviharju E, Moisander S, Laurila J (2005) Improved green plant regeneration rates from oat anther culture and the agronomic performance of some DH lines. Plant Cell Tissue Organ Cult 81:1-9

Kiviharju E, Moisander S, Tanhuanpää P (2017) Oat anther culture and use of DH-lines for genetic mapping. In: Gasparis S (ed) Oat. Methods in molecular biology, vol 1536. Humana Press, New York, pp 71-93

Kiviharju E, Pehu E (1998) The effect of cold and heat pretreatments on anther culture response of Avena sativa and A. sterilis. Plant Cell Tissue Organ Cult 54:97-104

Kiviharju E, Puolimatka M, Saastamoinen M, Hovinen S, Pehu E (1998) The effect of genotype on anther culture response of cultivated and wild oats. Agric Food Sci Finl 7:409-422

Kiviharju E, Puolimatka M, Saastamoinen M, Pehu E (2000) Extension of anther culture to several genotypes of cultivated oats. Plant Cell Rep 19:674-679

Maluszynski M, Kasha KJ, Szarejko I (2003) Published protocols for other crop plant species. In: Maluszynski M, Kasha KJ, Forster BP, Szarejko I (eds) Doubled haploid production in crop plants. Springer, Dordrecht, pp 309-336

Maraschin SF, de Priester W, Spaink HP, Wang M (2005) Androgenic switch: an example of plant embryogenesis from the male gametophyte perspective. J Exp Bot 56:1711-1726

Marcińska I, Nowakowska A, Skrzypek E, Czyczyło-Mysza I (2013) Production of double haploids in oat (Avena sativa L.) by pollination with maize (Zea mays L.). Cent Eur J Biol 8:306-313

Mayakaduwa DMRG, Silva TD (2017) A cytological indicator allows rapid assessment of microspore maturity, leading to improved in vitro anther response in Indica rice (Oryza sativa L.). In Vitro Cell Dev Biol-Plant 53(6):591-597

Murashige T, Skoog F (1962) A revised medium for rapid growth and bioassays with tobacco tissue cultures. Physiol Plant 15:473-497

Murovec J, Bohanec B (2012) Haploids and doubled haploids in plant breeding. In: Abdurakhmonov I (Ed.), Plant breeding. InTech Europe, Croatia, pp. 87-106 
Nowakowska A, Skrzypek E, Marcińska I, Czyczyło-Mysza I, Dziurka K, Juzoń K, Cyganek K, Warchoł M (2015) Application of chosen factors in the wide crossing method for the production of oat doubled haploids. Open Life Sci 10:112-118

Ouyang TW, Jia SE, Zhang C, Chen X, Feng G (1989) A new synthetic medium (W14) for wheat anther culture. Annual report 1987-1988. Institute of Genetics Academia Sinica, Beijing, pp 91-92

Oleszczuk S, Sowa S, Zimny J (2006) Androgenic response to preculture stress in microspore cultures of barley. Protoplasma 228:95-100

Ponitka A, Ślusarkiewicz-Jarzina A (2009) Regeneration of oat androgenic plants in relation to induction media and culture condition of embryo-like structures. Acta Soc Bot Pol 78(3): 209-213

Rines HW (1983) Oat anther culture: genotype effects on callus initiation and the production of haploid plant. Crop Sci 23:268-227

Rines HW, Riera-Lizarazu O, Nunez VM, Davis DW, Phillips RL (1997) Oat haploids from anther culture and from wide hybridizations. In: Jain SM, Sopory SK, Veilleux RE (eds) In vitro haploid production in higher plants, vol 4. Kluwer, Dordrecht, pp 205-221

Sidhu PK, Davies PA (2009) Regeneration of fertile green plants from oat isolated microspore culture. Plant Cell Rep 28:571-577

Sidhu PK, Howes NK, Aung T, Zwer PK, Davies PA (2006) Factors affecting haploid production following oat $\times$ maize hybridization. Plant Breed 125:1-6
Shariatpanahi ME, Bal U, Heberle-Bors E, Touraev A (2006) Stresses applied for the re-programming of plant microspores towards in vitro embryogenesis. Physiol Plant 127:519-534

Skrzypek E, Czyczyło-Mysza I, Marcińska I, Wędzony M (2008) Prospects of androgenetic induction in Lupinus spp. Plant Cell Tissue Organ Cult 94:131-137

Smykal P, Pechan PM (2000) Stress, as assessed by the appearance of sHsp transcripts, is required but not sufficient to initiate androgenesis. Physiol Plant 110:135-143

Sood S, Dwivedi S (2015) Doubled haploid platform: an accelerated breeding approach for crop improvement. In: Bahadur B, Venkat Rajam M, Sahijram L, Krishnamurthy K (eds) Plant biology and biotechnology. Springer, New Delhi, pp 89-111

Sun CS, Lu T-G, Söndahl MR (1991) Anther culture of naked oat and the establishment of its haploid suspension cell. Acta Bot Sin 33:417-420

Ślusarkiewicz-Jarzina A, Ponitka A (2007) The effect of physical medium state on anther culture response in polish cultivated oat (Avena sativa L.). Acta Biol Cracov Ser Bot 49:27-31

Wang XZ, Hu H (1984) The effect of potato II medium for 279 triticale anther culture. Plant Sci Lett 36:237-239

Warchoł M, Skrzypek E, Nowakowska A, Marcińska I, Czyczyło-Mysza I, Dziurka K, Juzoń K, Cyganek K (2016) The effect of auxin and genotype on the production of Avena sativa L. doubled haploid lines. Plant Growth Regul 78:155-156 